\title{
The Use of Low-EPA Fish Oil for Long-Chain Polyunsaturated Fatty Acid Supplementation of Preterm Infants
}

\author{
ALEXANDRE LAPILLONNE, JEAN-CHARLES PICAUD, VÉRONIQUE CHIROUZE, \\ JOËLLE GOUDABLE, BERNADETTE REYGROBELLET, \\ OLIVIER CLARIS, AND BERNARD L. SALLE \\ Department of Neonatology [A.L., J.C.P., B.R., O.C., B.L.S], Department of Biochemistry [J.G] and \\ Human Nutrition Research Centre [A.L., J.C.P., J.G, B.L.S], Hôpital Edouard Herriot, 69437 Lyon, \\ France; and IMEDEX, 69630 Chaponost, France [V.C.]
}

\begin{abstract}
Because docosahexaenoic acid (DHA) may be an essential nutrient for the visual and early cognitive development of preterm infants, DHA enrichment of preterm formulas has been recommended. This randomized trial was designed to study the n- 6 and n-3 fatty acid status of healthy preterm infants fed a formula enriched with a low eicosapentaenoic-fish oil until 4 mo corrected age compared with that of infants fed a standard formula. A reference group of breast-fed infants was studied concurrently. The fatty acid content of red blood cell (RBC) phospholipid was assessed at enrollment, hospital discharge, expected term, and 3 and 6 mo postterm. The DHA content of $\mathrm{RBC}$ phospholipid was higher in infants fed the enriched versus the standard formula at hospital discharge, expected term, and 3 and 6 mo postterm. However, compared with infants fed the standard formula, infants fed the enriched formula had also higher RBC phospholipid eicosapentaenoic content $(0.69 \pm$ $0.15 \%$ versus $0.25 \pm 0.12 \%, p<0.001$ ), and lower $\mathrm{RBC}$ phospholipid arachidonic acid content $(15.1 \pm 0.93 \%$ versus
\end{abstract}

\section{ABSTRACT}

$18.8 \pm 0.89 \% ; p<0.001)$. We conclude that supplementing preterm infants with low-eicosapentaenoic fish oil is effective in improving DHA status, but results in worsening of $n-6$ fatty acid status. We speculate that preterm infants may require a dietary supply of arachidonic acid as well as DHA if the same fatty acid status as that of breast-fed infants is to be achieved. (Pediatr Res 48: 835-841, 2000)
Abbreviations
AA, arachidonic acid or $20: 4 n-6$
DHA, docosahexaenoic acid or 22:6n-3
EPA, eicosapentaenoic acid or 20:5n-3
LA, linoleic acid or $18: 2 n-6$
LNA, linolenic acid or 18:3n-3
LC-PUFA, long-chain polyunsaturated fatty acid, 20-22 carbon chain length
RBC, red blood cells

The availability of LC-PUFA, such as AA and DHA, is important for early human growth and development (1). Recent studies using stable isotopes have demonstrated that humans, including preterm infants, are capable of synthesizing AA and DHA from linoleic and linolenic acids, respectively $(2,3)$. However, endogenous synthesis of $n-3$ fatty acids apparently does not meet the needs of preterm infants for these fatty acids, as suggested by the fatty acid composition of plasma and $\mathrm{RBC}$ lipids (4-6). Because preterm infants fed unsupplemented formulas resulting in lower levels of n-3 LC-PUFA in plasma and tissue lipids may be at risk for impaired neural or visual system development (7-12), LC-PUFA enrichment of preterm formulas has been recommended (13-16).

Correspondence: Alexandre Lapillonne, M.D., Ph.D., USDA/ARS Children's Nutrition Research Center, Department of Pediatrics, Baylor College of Medicine, 1100 Bates Street, Houston, Texas 77030-2600, U.S.A.

This work was supported by Blédina SA, Villefranche, France.
An easy way to enrich formula with n-3 LC-PUFA is to add fish oil, which contains n-3 LC-PUFA. In earlier trials, preterm infants were fed formulas supplemented with fish oils containing DHA $(0.2-0.35 \%)$ and high levels of EPA $(0.30-0.65 \%)$ from approximately $3 \mathrm{wk}$ of age until 2 mo (4) or 9 mo past expected term (5). The DHA status of supplemented infants was greatly improved, accompanied by better visual acuity at 4 mo postterm $(7,11,12,17)$. However, in one trial, the supplemented group exhibited poor overall growth throughout the first year of life (18), which was significantly correlated with lower plasma phosphatidylcholine (PC) AA; this was thought to result from the high EPA content of the supplemented formula (19).

A more recent study evaluated the use of low-EPA fish oil as a supplement for preterm formula (9). Infants were fed an enriched formula (0.2\% DHA; $0.06 \% \mathrm{EPA})$ until 2 mo past expected term. By this time, infants fed the enriched formula 
Table 1. Fatty acid profiles (percentage of total fatty acids by weight) of the standard and LC-PUFA enriched formulas fed in the study.* Fatty acid profile of breast milk is also reported $\%$

\begin{tabular}{|c|c|c|c|c|c|}
\hline \multirow[b]{2}{*}{ Fatty acids } & \multirow[b]{2}{*}{ Human milk } & \multicolumn{2}{|c|}{ Standard formula } & \multicolumn{2}{|c|}{ Enriched formulas } \\
\hline & & PTF & $\mathrm{TF}$ & PTF & $\mathrm{TF}$ \\
\hline C6:0 & $0.17 \pm 0.03$ & 0.35 & 0.41 & 0.34 & 0.41 \\
\hline $\mathrm{C} 10: 0$ & $2.12 \pm 0.57$ & 8.13 & 1.87 & 8.74 & 2.09 \\
\hline $\mathrm{C} 12: 0$ & $8.13 \pm 2.48$ & 4.43 & 13.52 & 4.02 & 15.28 \\
\hline C14:0 & $9.36 \pm 2.26$ & 2.13 & 5.33 & 2.08 & 6.20 \\
\hline $\mathrm{C} 16: 0$ & $23.35 \pm 1.99$ & 15.23 & 18.99 & 14.81 & 17.86 \\
\hline C20:0 & $0.21 \pm 0.03$ & 0.22 & 0.26 & 0.14 & 0.25 \\
\hline C18:1 n-9/n-7 & $31.69 \pm 3.83$ & 31.69 & 32.17 & 30.64 & 31.66 \\
\hline C18:2 n-6 & $10.98 \pm 3.71$ & 17.95 & 18.23 & 17.78 & 17.17 \\
\hline C20:4 n-6 & $0.56 \pm 0.08$ & - & - & 0.02 & 0.03 \\
\hline C18:3 n-3 & $0.74 \pm 0.15$ & 1.60 & 1.57 & 1.10 & 1.07 \\
\hline$C 20: 5 n-3$ & $0.24 \pm 0.21$ & - & - & 0.05 & 0.09 \\
\hline $\mathrm{FA}(\mathrm{mg} / 100 \mathrm{~mL})$ & $3.10 \pm 0.3$ & 3.74 & 3.49 & 3.60 & 3.51 \\
\hline
\end{tabular}

* Preterm standard and enriched formulas (PTF) were fed from inclusion until expected term; thereafter, term standard and enriched formulas (TF) were fed until 4 mo postterm.

$\dagger$ Mean $+/-$ SD values from samples collected from 5 of the 10 breast-fed infants.

had the same RBC phospholipid content of DHA as at birth but it decreased as soon as the supplemented formula was discontinued. No significant variation of RBC phospholipid AA content was observed in infants fed the enriched formula. This study suggests that DHA supplementation for more than 2 mo postterm is necessary for optimal accumulation of DHA, and also that supplementation with low-EPA fish oil may prevent the adverse effects of fish oil on n-6 LC-PUFA status and growth.

To evaluate this possibility, we have undertaken a randomized study to assess the effect of feeding a formula enriched with a high DHA low-EPA fish oil until 4 mo postterm on the LC-PUFA status of preterm infants. A nonrandomized group of breast-fed infants was also studied concurrently as a reference group.

\section{METHODS}

Subjects. This longitudinal, prospective randomized study of healthy preterm infants was conducted at the Department of Neonatology of the Edouard Herriot Hospital, Lyon, France. The preterm infants enrolled were appropriate for gestational age according to the curves described by Usher and McLean (20). Birth weight was between 700 and $1500 \mathrm{~g}$. Gestational age was determined from the date of the mother's last menstrual period and was confirmed by early ultrasound and clinical evaluation at birth (21). Exclusion criteria included major neonatal morbidity (e.g. congenital anomalies, respiratory treatment for more than $10 \mathrm{~d}$, congenital infection, necrotizing enterocolitis, and bowel resection), a postnatal age of more than $21 \mathrm{~d}$, requirement for supplemental oxygen or treatments (e.g. diuretics and corticosteroids) that could influence growth and development, a failure to achieve full enteral feeding of $150 \mathrm{~mL} / \mathrm{kg} / \mathrm{d}$ by a postnatal age of $21 \mathrm{~d}$, and a maternal history of cocaine/alcohol abuse, diabetes, hyperlipidemia, or abnormal dietary patterns (strict vegetarian diets).

A research nurse monitored the infants enrolled during hospitalization. Infants were weighed daily using a calibrated infant balance. Length was determined weekly to the nearest $0.1 \mathrm{~cm}$ using an infant measuring board. Head circumference also was measured weekly at the largest occipitofrontal circumference with a nonstretchable paper tape. Volume of intake and feeding tolerance were recorded daily. The attending neonatologist and resident physicians who were familiar with the study provided clinical care. After discharge, type of milk and volume of formula intake were recorded daily by the parents. Intake of formula was determined by the difference in prefeeding and postfeeding weights of each feeding unit offered. Weight, length, and head circumference were measured by the research nurse at each visit (i.e. expected term, 3 and 6 mo postterm). No infants were excluded from the study, either during hospitalization or during the outpatient follow-up phase of the study.

Diets. Enteral feeding of all infants was started during the first week of life with pooled, pasteurized breast milk (Lyon Lactarium, France) as usual in the unit. For the formula-fed infants, permission for study entry was sought only if the mothers had previously decided not to breast-feed their infants. Twenty-three infants were randomly assigned to receive either a control formula $(n=12)$ or a formula with LC-PUFA $(n=$ 11). Formula feeding began during the first 3 wk of life. After enrollment, all infants were fed exclusively with their assigned formula. Preterm formulas were fed from enrollment through expected term, at which time term formulas with or without LC-PUFA, according to assignment, were fed. These were fed through 4 mo postterm, when all infants were switched to a standard formula without LC-PUFA. 
Table 2. Clinical data of the preterm infants according to their diet; * they received their own mother's milk (human milk) or were randomly assigned to receive a standard formula without LC-PUFA or an enriched formula with LC-PUFA. ${ }^{\dagger}$

\begin{tabular}{|c|c|c|c|c|c|c|}
\hline & $n$ & $\begin{array}{c}\text { Postnatal age } \\
\text { (d) }\end{array}$ & $\begin{array}{c}\text { Gestational } \\
\text { age (wk) }\end{array}$ & Weight (g) & $\begin{array}{l}\text { Length } \\
\text { (cm) }\end{array}$ & $\mathrm{HC}(\mathrm{cm})$ \\
\hline \multicolumn{7}{|l|}{ Birth } \\
\hline Human milk & 10 & - & $28.8 \pm 1.9$ & $1325 \pm 138$ & $40.4 \pm 2.0$ & $26.9 \pm 1.3$ \\
\hline Standard formula & 12 & - & $29.7 \pm 1.4$ & $1235 \pm 161$ & $39.3 \pm 2.2$ & $27.5 \pm 1.1$ \\
\hline Enriched formula & 11 & - & $29.4 \pm 1.4$ & $1275 \pm 172$ & $39.6 \pm 2.4$ & $27.3 \pm 1.9$ \\
\hline \multicolumn{7}{|l|}{ Inclusion } \\
\hline Human milk & 10 & $16.3 \pm 3.3$ & $31.1 \pm 2.0$ & $1353 \pm 179$ & $41.2 \pm 2.1$ & $27.3 \pm 1.4$ \\
\hline Standard formula & 12 & $17.1 \pm 3.0$ & $32.1 \pm 1.6$ & $1313 \pm 236$ & $39.4 \pm 1.6$ & $28.0 \pm 1.4$ \\
\hline Enriched formula & 11 & $17.4 \pm 4.0$ & $31.8 \pm 1.2$ & $1286 \pm 205$ & $39.6 \pm 1.8$ & $27.5 \pm 1.9$ \\
\hline \multicolumn{7}{|l|}{ Discharge } \\
\hline Human milk & 10 & $41 \pm 7.1$ & $34.7 \pm 1.4$ & $2001 \pm 141$ & $42.8 \pm 1.2$ & $30.9 \pm 1$ \\
\hline Standard formula & 12 & $41.3 \pm 7.7$ & $35.6 \pm 1.1$ & $2043 \pm 247$ & $43.8 \pm 2.4$ & $32 \pm 1.4$ \\
\hline Enriched formula & 11 & $42.5 \pm 8.8$ & $35.4 \pm 1$ & $2007 \pm 107$ & $43.1 \pm 1$ & $31.1 \pm 1.2$ \\
\hline \multicolumn{7}{|l|}{ Expected term } \\
\hline Human milk & 10 & $77.2 \pm 12.6$ & $39.8 \pm 1$ & $3312 \pm 564$ & $49.2 \pm 1.4$ & $34.8 \pm 0.7$ \\
\hline Standard formula & 12 & $77.0 \pm 11.6$ & $40.7 \pm 0.8$ & $3284 \pm 463$ & $49.0 \pm 2.1$ & $35.5 \pm 1.8$ \\
\hline Enriched formula & 11 & $71.9 \pm 10.7$ & $39.8 \pm 1.6$ & $2966 \pm 440$ & $47.7 \pm 1.4$ & $34.3 \pm 2.2$ \\
\hline \multicolumn{7}{|l|}{3 mo postterm } \\
\hline Human milk & 10 & $169.4 \pm 11$ & $53.0 \pm 1.4$ & $6013 \pm 824$ & $59.6 \pm 1.9$ & $40.9 \pm 1.0$ \\
\hline Standard formula & 12 & $163.3 \pm 11.5$ & $53.0 \pm 1.8$ & $5266 \pm 722$ & $58.1 \pm 2.3$ & $39.4 \pm 2.9$ \\
\hline Enriched formula & 11 & $163.5 \pm 11.5$ & $52.7 \pm 1.1$ & $5426 \pm 765$ & $58.2 \pm 1.6$ & $39.7 \pm 1.9$ \\
\hline \multicolumn{7}{|l|}{6 mo postterm } \\
\hline Human milk & 10 & $262.9 \pm 17.6$ & $66.4 \pm 1.5$ & $7775 \pm 1002$ & $66.4 \pm 4.3$ & $44.2 \pm 1.3$ \\
\hline Standard formula & 12 & $257.7 \pm 9.1$ & $66.5 \pm 1.1$ & $6708 \pm 845$ & $65.0 \pm 2.5$ & $43.7 \pm 2.1$ \\
\hline Enriched formula & 11 & $262.4 \pm 18.5$ & $66.8 \pm 1.7$ & $7109 \pm 1109$ & $65.7 \pm 2.4$ & $42.5 \pm 2.0$ \\
\hline
\end{tabular}

HC, head circumference.

* Results are expressed as mean $+/-$ SD.

$\dagger$ No significant differences have been found between groups by using the Kruskal-Wallis method and Dunn's post hoc analysis.

The formulas were specially prepared for the study. All formulas were ready-to-feed, and met or exceeded the levels of energy, protein, and micronutrients as recommended for preterm and term formulas by the European Society for Pediatric Gastroenterology and Nutrition $(13,22)$. The standard and enriched formulas differed only in the amounts and sources of dietary fatty acids. The oil blend consisted of vegetable oils. The control formulas contained no added LC-PUFA, whereas the enriched formulas provided DHA from a high-DHA lowEPA fish oil (ROPUFA "30" n-3 INF oil, Roche, Basel, Switzerland), which contains at least $30 \%$ of LC-PUFA in the form of glycerides such as docosapentaenoic acid, EPA, and DHA (ratio of DHA to EPA $=4.8 / 1$ ). The DHA content of the supplemented formulas was within the ranges reported for human milk in the French and European populations $(6,23)$. Both formulas provided the same amount of total fatty acids as well as the same total amount of n-3 and n- 6 fatty acids. Full details of the fatty acid composition of the formulas are given in Table 1.

A nonrandomized group of 10 breast-fed infants was also included in this study. From enrollment until discharge, these infants received $100 \%$ of their enteral intake as prefrozen milk from their mother supplemented with a standardized human milk fortifier (Eoprotin ${ }^{\circledR}$, Milupa, Friedrichsdorf, Germany) to assure adequate macro- and micronutrient intake (24). After discharge, the mothers were encouraged to continue breastfeeding as long as possible. If mothers were unable to provide sufficient human milk for full feeding, the standard formula without LC-PUFA was used to supplement the feeding until the end of the study.
All parents were advised about feeding in a uniform manner. The goal was to ensure that each infant be allowed to consume his or her desired intake. Formulas were provided to parents without restriction. Dietary histories were obtained at each visit to estimate the volume of formula intake and to obtain information about use of other nutrient sources. Parents were advised against use of solid food before 4 mo corrected age and advised that formula should remain the major food source for their infant until 6 mo corrected age.

Blood sampling and fatty acid analysis. The composition of fatty acids in total RBC phospholipids was measured to assess the effect of dietary fatty acids to ensure compliance. A 1-mL blood sample was obtained from each infant by venipuncture at enrollment and discharge, as well as expected term and at 3 mo and 6 mo postterm. No blood sample was taken within $10 \mathrm{~d}$ after a blood transfusion, except for one breast-fed infant who received a blood transfusion $7 \mathrm{~d}$ before enrollment. However, removing the data from this sample changes neither the mean value nor the statistical analysis. After removal of plasma by centrifugation, RBC were washed and immediately resuspended in methanol containing BHT as an antioxidant. Samples were stored under these conditions at $-70^{\circ} \mathrm{C}$ until analysis. Lipid extraction was performed within $2 \mathrm{wk}$ of sample collection.

During the hospital stay, samples of human milk were obtained from five of the breast-feeding mothers and stored at $-70^{\circ} \mathrm{C}$ until analysis for total fat and fatty acid composition. The fatty acid composition observed was similar to that previously published in a French population (6). 
Table 3. Red blood cell phospholipid contents of n-6 fatty acids (percentage of total fatty acids by weight) of preterm infants fed human milk, standard formula (control), and an n-3 LC-PUFA-supplemented formula (low EPA-fish oil) until 4 mo postterm*

\begin{tabular}{|c|c|c|c|c|}
\hline & $\begin{array}{l}\text { Human milk } \\
\quad(n=10)\end{array}$ & $\begin{array}{l}\text { Standard formula } \\
\quad(n=12)\end{array}$ & $\begin{array}{l}\text { Enriched formula } \\
\quad(n=11)\end{array}$ & $p \dagger$ \\
\hline \multicolumn{5}{|l|}{ C18:2 n-6 } \\
\hline Enrollment & $7.88 \pm 2.03$ & $8.11 \pm 1.37$ & $8.26 \pm 1.27$ & 0.65 \\
\hline Term & $11.3 \pm 0.81$ & $11.7 \pm 0.75$ & $11.6 \pm 1.35$ & 0.54 \\
\hline 3 mo postterm & $12.8 \pm 1.33$ & $13.3 \pm 0.97$ & $12.5 \pm 0.92$ & 0.18 \\
\hline 6 mo postterm & $12.6 \pm 1.48$ & $13.3 \pm 0.97$ & $12.1 \pm 1.10$ & 0.08 \\
\hline Discharge & $2.30 \pm 0.28$ & $2.51 \pm 0.51$ & $2.57 \pm 0.46$ & 0.35 \\
\hline Term & $2.20 \pm 0.38 \mathrm{a}$ & $2.72 \pm 0.54 \mathrm{~b}$ & $2.47 \pm 0.44$ & 0.03 \\
\hline 3 mo postterm & $2.11 \pm 0.37$ & $2.44 \pm 0.39$ & $2.17 \pm 0.49$ & 0.13 \\
\hline 6 mo postterm & $1.99 \pm 0.25 \mathrm{a}$ & $2.40 \pm 0.31 \mathrm{~b}$ & $2.43 \pm 0.61$ & 0.02 \\
\hline \multicolumn{5}{|l|}{$C 20: 4$ n-6 } \\
\hline Enrollment & $19.9 \pm 1.42$ & $19.5 \pm 1.40$ & $19.8 \pm 0.80$ & 0.86 \\
\hline \multicolumn{5}{|l|}{$\mathrm{C} 22: 4 \mathrm{n}-6$} \\
\hline Enrollment & $3.39 \pm 0.35$ & $3.52 \pm 0.51$ & $3.38 \pm 0.42$ & 0.90 \\
\hline Discharge & $3.50 \pm 0.25$ & $3.73 \pm 0.32$ & $3.48 \pm 0.26$ & 0.10 \\
\hline Term & $4.32 \pm 0.62 \mathrm{a}$ & $4.40 \pm 0.78 \mathrm{a}$ & $3.61 \pm 0.28 \mathrm{~b}$ & 0.004 \\
\hline 3 mo postterm & $4.61 \pm 0.60 \mathrm{a}$ & $4.65 \pm 0.74 \mathrm{a}$ & $3.03 \pm 0.41 \mathrm{~b}$ & $<0.0001$ \\
\hline 6 mo postterm & $4.34 \pm 0.41 \mathrm{a}$ & $4.21 \pm 0.73 \mathrm{a}$ & $3.43 \pm 0.53 b$ & 0.003 \\
\hline \multicolumn{5}{|l|}{$\mathrm{C} 22: 5 \mathrm{n}-6$} \\
\hline Enrollment & $1.13 \pm 0.31$ & $1.18 \pm 0.21$ & $1.17 \pm 0.37$ & 0.71 \\
\hline Discharge & $1.00 \pm 0.16$ & $1.09 \pm 0.23$ & $1.02 \pm 0.24$ & 0.60 \\
\hline Term & $0.98 \pm 0.15$ & $1.20 \pm 0.28 \mathrm{a}$ & $0.92 \pm 0.12 b$ & 0.005 \\
\hline 3 mo postterm & $1.12 \pm 0.27 \mathrm{a}$ & $1.18 \pm 0.18 \mathrm{a}$ & $0.82 \pm 0.10 \mathrm{~b}$ & 0.002 \\
\hline 6 mo postterm & $1.03 \pm 0.17$ & $1.03 \pm 0.18$ & $0.89 \pm 0.14$ & 0.10 \\
\hline
\end{tabular}

Values with different letters are significantly different $(p<0.05)$. HM, human milk; SF, standard formula; EF, enriched formula.

* Results expressed as mean $+/-$ SD.

$\dagger$ Kruskal-Wallis method and Dunn's post hoc analysis for between-group comparison.

Fatty acid analysis of blood and milk samples was performed as previously described (6). Lipids from $\mathrm{RBC}$ and milks were extracted with methanol/chloroform (1/2). Lipid classes were separated by thin-layer chromatography. The silica gel bands containing RBC phospholipids were immediately scraped and methylated with boron trifluoride in methanol. The fatty acid methyl esters were separated and quantitated by capillary gas liquid chromatography. Identification of individual fatty acids was accomplished by comparison with standard mixtures purchased from Sigma Chemical Co. (St. Louis, MO, U.S.A.). Individual fatty acids were quantified by automatic integration and expressed as percentages of the total fatty acids with 14 or more carbons.

Ethics. The project was approved by the local ethics committee. All parents were informed of the details of the study, and written consent was obtained in all cases.

Statistical methods. Statistical analysis was performed using SigmaStat (SPSS Inc., Chicago, IL, U.S.A.). Sample sizes were estimated to allow detection of a 1.2 SD difference (6) in RBC phospholipid DHA contents between formula-fed groups (power $=80 \% ; p<0.05$ ). The final sample size required is seven infants. Anticipating a $30 \%$ loss to follow-up, we planned a recruitment of 9 infants for each of the three diet groups, and achieved enrollment of 10-12 per groups. Descriptive statistics were computed for all dependent variables. The Kruskal-Wallis analysis of variance on ranks was used to compare outcome variables of the three experimental groups. When $p$ values were significant, multiple comparisons were performed; because the sample sizes of the diet groups differed, the Dunn's test with pairwise multiple comparison procedures was used. Correlations between fatty acid contents were calculated by Spearman rank correlations. Results were considered significant if the $p$ value was less than or equal to 0.05 .

\section{RESULTS}

Inclusion characteristics and growth. The clinical characteristics at birth and at enrollment did not differ significantly 
among the feeding groups (Table 2). All groups were fed identically during the pre-enrollment period and there were no statistically significant differences between groups in the total amount of milk fed, the proportion of breast milk fed, or the amount of enteral intake at enrollment. Growth of the three groups did not differ during the study (Table 2). Mean values for weight, length, and head circumference at the various ages were comparable with those usually observed in studies of preterm infants.

RBC phospholipid fatty acid concentrations. The fatty acid profiles of the RBC phospholipids of the three groups were similar at enrollment. No significant differences in the content of saturated and monounsaturated fatty acids were observed between groups during the course of the study (data not shown).

The difference in dietary lipid composition, in contrast, had a strong influence on the n- 6 and n-3 fatty acid pattern of RBC phospholipids of formula-fed infants (Tables 3 and 4). Because the standard formula contained no LC-PUFA, infants fed this formula had, as expected, a continuous decrease in RBC phospholipid DHA content from enrollment through the end of the study, when it was $50 \%$ lower than observed at enrollment (Table 4). During the same period, RBC phospholipid AA content remained stable in this group (Table 3 ).
In contrast, the RBC phospholipid DHA content of infants fed the enriched formula was significantly higher than that of the standard formula-fed group during the entire study, peaking at $9 \%$ of total fatty acids at 3 mo postterm. Despite the low content of EPA in the formula, the RBC phospholipid content of EPA increased in the supplemented formula group from enrollment until 3 mo postterm. A dramatic decrease in RBC phospholipid content of AA also was observed in this group. RBC phospholipid AA content at 3 mo and 6 mo postterm were significantly lower than those observed in the standard formula group. However, at 6 mo postterm (e.g. 2 mo after the supplementation was stopped) the RBC phospholipid AA content of this group was $14 \%$ higher than at 3 mo.

No statistically significant variation in the total $n-6$ and n-3 fatty acid contents of RBC phospholipid was observed in the breast-fed group between enrollment and discharge. After discharge, mothers progressively stopped breast-feeding their infants and commenced feeding standard formula. As a consequence, the total amount of breast milk fed dropped from $100 \%$ at discharge to $71 \%$ at term and only 3 of the 10 mothers continued to breast-feed their infant beyond expected term. Consequently, the RBC phospholipid fatty acid pattern changed dramatically after discharge, and tended to resemble that of the standard formula group.

Table 4. Red blood cell phospholipid content of n-3 fatty acids (percentage of total fatty acids by weight) of preterm infants fed human milk, standard formula (control), and an n-3 LC-PUFA-supplemented formula (low EPA-fish oil) until 4 mo postterm*

\begin{tabular}{|c|c|c|c|c|}
\hline & $\begin{array}{l}\text { Human milk } \\
\quad(n=10)\end{array}$ & $\begin{array}{l}\text { Standard formula } \\
\quad(n=12)\end{array}$ & $\begin{array}{l}\text { Enriched formula } \\
\quad(n=11)\end{array}$ & $p \dot{\phi}$ \\
\hline \multicolumn{5}{|l|}{ C18:3 n-3 } \\
\hline Enrollment & $0.07 \pm 0.09$ & $0.08 \pm 0.07$ & $0.12 \pm 0.12$ & 0.64 \\
\hline Term & $0.13 \pm 0.07^{\mathrm{a}}$ & $0.11 \pm 0.07^{\mathrm{a}}$ & $0.03 \pm 0.04^{\mathrm{b}} \mathrm{b}$ & 0.003 \\
\hline 3 mo postterm & $0.15 \pm 0.05^{\mathrm{a}}$ & $0.17 \pm 0.09^{\mathrm{a}}$ & $0.09 \pm 0.04^{\mathrm{b}}$ & 0.02 \\
\hline 6 mo postterm & $0.16 \pm 0.04$ & $0.17 \pm 0.04$ & $0.14 \pm 0.03$ & 0.07 \\
\hline Discharge & $0.56 \pm 0.28$ & $0.35 \pm 0.13$ & $0.42 \pm 0.10$ & 0.15 \\
\hline Term & $0.47 \pm 0.17^{\mathrm{a}}$ & $0.28 \pm 0.12^{\mathrm{b}}$ & $0.45 \pm 0.14$ & 0.01 \\
\hline 3 mo postterm & $0.28 \pm 0.13^{\mathrm{a}}$ & $0.25 \pm 0.12^{\mathrm{a}}$ & $0.69 \pm 0.15^{\mathrm{b}}$ & $<0.0001$ \\
\hline 6 mo postterm & $0.53 \pm 0.16$ & $0.45 \pm 0.19$ & $0.55 \pm 0.21$ & 0.19 \\
\hline \multicolumn{5}{|l|}{$\mathrm{C} 22: 5 \mathrm{n}-3$} \\
\hline Enrollment & $1.02 \pm 0.45$ & $0.98 \pm 0.28$ & $1.06 \pm 0.52$ & 0.98 \\
\hline \multicolumn{5}{|l|}{$\mathrm{C} 22: 6 \mathrm{n}-3$} \\
\hline Enrollment & $6.12 \pm 0.83$ & $5.89 \pm 0.87$ & $6.02 \pm 1.27$ & 0.80 \\
\hline Discharge & $6.39 \pm 0.67^{\mathrm{a}}$ & $4.86 \pm 0.47^{\mathrm{b}}$ & $6.57 \pm 0.59^{\mathrm{a}}$ & $<0.0001$ \\
\hline Term & $5.52 \pm 1.09^{\mathrm{a}}$ & $3.79 \pm 0.65^{\mathrm{b}}$ & $6.88 \pm 0.76^{\mathrm{a}}$ & $<0.0001$ \\
\hline 3 mo postterm & $3.91 \pm 1.32^{\mathrm{a}}$ & $2.95 \pm 0.69^{\mathrm{a}}$ & $9.22 \pm 0.92^{\mathrm{b}}$ & $<0.0001$ \\
\hline 6 mo postterm & $3.51 \pm 0.82^{\mathrm{a}}$ & $2.78 \pm 0.61^{\mathrm{a}}$ & $6.61 \pm 1.03^{b}$ & $<0.0001$ \\
\hline \multicolumn{5}{|l|}{ Total n-3 } \\
\hline Enrollment & $7.6 \pm 0.7$ & $7.3 \pm 0.9$ & $7.6 \pm 1.5$ & 0.59 \\
\hline Discharge & $8.6 \pm 1.0^{\mathrm{a}}$ & $6.8 \pm 0.8^{b}$ & $8.4 \pm 0.7^{\mathrm{a}}$ & 0.003 \\
\hline Term & $7.9 \pm 1.4^{\mathrm{a}}$ & $5.9 \pm 0.7^{b}$ & $8.7 \pm 0.7^{\mathrm{a}}$ & $<0.0001$ \\
\hline 3 mo postterm & $6.4 \pm 1.6^{\mathrm{a}}$ & $5.4 \pm 0.8^{\mathrm{a}}$ & $11.5 \pm 1.1^{\mathrm{b}}$ & $<0.0001$ \\
\hline 6 mo postterm & $6.5 \pm 1.0^{\mathrm{a}}$ & $5.8 \pm 0.9^{\mathrm{a}}$ & $9.3 \pm 1.3^{\mathrm{b}}$ & $<0.0001$ \\
\hline
\end{tabular}

Values with different letters are significantly different $(p<0.05)$. HM, human milk; SF, standard formula; EF, enriched formula.

* Results expressed as mean $+/-\mathrm{SD}$.

$\dagger$ Kruskal-Wallis method and Dunn’s post hoc analysis for between-group comparison. 
Across all infants, there was a statistically significant positive correlation between RBC phospholipid DHA content and RBC phospholipid EPA content at term as well as at $3 \mathrm{mo}$ and 6 mo postterm $(r=0.46, p=0.008 ; r=0.90, p=0.0001$; and $r=0.39, p=0.02$, respectively). These correlations also were statistically significant at 3 mo postterm when human milk and enriched formula-fed groups were examined separately $(r=$ $0.80, p=0.005 ; r=0.74, p=0.01$, respectively).

\section{DISCUSSION}

This randomized study was designed to assess the effects of feeding a preterm formula supplemented with low-EPA fish oil versus a standard formula until 4 mo postterm on the LCPUFA status of healthy preterm infants. One goal of our study was to determine whether deterioration of DHA status before 6 mo postterm could be prevented. Indeed, a short period of DHA supplementation, until term (6) or until 2 mo (9), is not sufficient to prevent a drop in DHA status during the ensuing months. By supplementing formula for 4 mo after term, normal RBC phospholipid DHA content was maintained until 6 mo postterm.

Another objective of the study was to determine whether the decrease of n-6 PUFA status associated with the use of a high-EPA fish oil could be prevented with the use of a lowEPA modified fish oil. In a previous trial, preterm infants fed such a source of LC-PUFA until 2 mo postterm had no significant decrease in RBC phospholipid AA content compared with the unsupplemented formula group (9). However, a decrease in the AA content was suspected because of a lower ratio of RBC PE AA to RBC PE DHA in the supplemented formula fed group throughout the study. In contrast to this earlier study, the LC-PUFA supplementation in our study had a strong influence on the RBC phospholipid content of AA, which decreased significantly over time in the LC-PUFA enriched group.

The observed decrease in RBC phospholipid AA status might be related to the higher RBC phospholipid content of EPA and/or DHA, which, in turn, might interfere with incorporation of AA into RBC phospholipids (1). The overall effect of these variations resulted, however, in no significant differences in total LC-PUFA content. This observed decrease in RBC phospholipid AA content might also be related to an inhibitory effect of EPA on the desaturation of linoleic acid to AA (1). By using a low-EPA fish oil, the $79 \%$ increase in RBC phospholipid EPA content between enrollment and 3 mo postterm in the supplemented group was not expected, but most likely resulted from the small amount of EPA present in the LC-PUFA supplement. However, the strong positive correlation between RBC phospholipid DHA and RBC phospholipid EPA suggests that retroconversion of DHA to EPA might also have occurred (25).

The RBC phospholipid DHA content of the breast milk-fed group remained stable until the mothers started to lessen and finally stop breast-feeding their infants. At 3 mo postterm, the DHA content of RBC phospholipid was slightly higher in the breast milk-fed group than the nonsupplemented group. At the end of the study, however, there was no statistically significant difference between the breast milk-fed group and the standard formula-fed group. This suggests that breast-feeding preterm infants only during the hospital stay is not sufficient to maintain levels of DHA in RBC phospholipids during the first several months of life. This finding is particularly important in countries where the average duration of breast-feeding is only a few weeks.

We conclude from this study that supplementing formulas with a low-EPA fish oil for 4 mo postterm is an effective way to maintain a normal DHA status during the period of supplementation and for 2 mo afterward. However, this supplementation resulted in an increase in RBC phospholipid n-3 fatty acids at the expense of $n-6$ fatty acids. Further studies are needed to explore the possible clinical effects of subnormal AA status in preterm infants, but it seems likely that formula-fed preterm infants require a dietary supply of preformed AA as well as DHA if the biochemical status of breast-fed infants is to be achieved.

Acknowledgments. The authors thank Jean B. Rochette de Lempdes and Alfred Galent for participation in the study design and many helpful discussions. We also thank Dr. William Heird for review of the manuscript, Dr. Roy Golsteyn and Leslie Loddeke for editorial assistance, and Dr. Gyslaine Claris for her help with the clinical follow-up of the infants.

\section{REFERENCES}

1. Innis SM 1991 Essential fatty acids in growth and development. Prog Lipid Res $30: 39-103$

2. Salem NJ, Wegher B, Mena P, Uauy R 1996 Arachidonic and docosahexaenoic acids are biosynthesized from their 18-carbon precursors in human infants. Proc Natl Acad Sci U S A 93:49-54

3. Sauerwald TU, Hachey DL, Jensen CL, Chen H, Anderson RE, Heird WC 1997 Intermediates in endogenous synthesis of C22:6 omega 3 and C20:4 omega 6 by term and preterm infants. Pediatr Res 41:183-187

4. Hoffman DR, Uauy R 1992 Essentiality of dietary omega 3 fatty acids for premature infants: plasma and red blood cell fatty acid composition. Lipids 27:886-895

5. Carlson SE, Cooke RJ, Rhodes PG, Peeples JM, Werkman SH, Tolley EA 1991 Long-term feeding of formulas high in linolenic acid and marine oil to very low birth weight infants: phospholipid fatty acids. Pediatr Res 30:404-412

6. Chirouze V, Lapillonne A, Putet G, Salle BL 1994 Red blood cell fatty acid composition in low-birth-weight infants fed either human milk or formula during the first months of life. Acta Paediatr Suppl 405:70-77

7. Carlson SE, Werkman SH, Rhodes PG, Tolley EA 1993 Visual-acuity development in healthy preterm infants: effect of marine-oil supplementation. Am J Clin Nutr 58:35-42

8. Carlson SE, Werkman SH 1996 A randomized trial of visual attention of preterm infants fed docosahexaenoic acid until two months. Lipids 31:85-90

9. Carlson SE, Werkman SH, Tolley EA 1996 Effect of long-chain n-3 fatty acid supplementation on visual acuity and growth of preterm infants with and without bronchopulmonary dysplasia. Am J Clin Nutr 63:687-697

10. Uauy DR, Birch EE, Birch DG, Hoffman DR 1994 Significance of omega 3 fatty acids for retinal and brain development of preterm and term infants. World Rev Nutr Diet $75: 52-62$

11. Birch DG, Birch EE, Hoffman DR, Uauy RD 1992 Retinal development in very-lowbirth-weight infants fed diets differing in omega-3 fatty acids. Invest Ophth Vis Sci $33: 2365-2376$

12. Birch EE, Birch DG, Hoffman DR, Uauy R 1992 Dietary essential fatty acid supply and visual acuity development. Invest Ophthalmol Vis Sci 33:3242-3253

13. ESPGAN 1991 Committee report. Comment on the content and composition of infant formulas. Acta Paediatr Scand 80:887-896.

14. Food and Agriculture Organization (FAO) of the United Nations and the World Health Organization 1994 Lipids in early development. In: FAO (ed) Fats and Oils in Human Nutrition, Report of a Joint Expert Consultation. FAO, Rome, pp 49-55

15. ISSFAL Board of Directors 1994 Recommendations for essential fatty acid requirements for infants formulae. ISSFAL Newsletter 1:4-5.

16. The Report of the British Nutrition Foundation's Task Force 1992 In: Unsaturated Fatty Acids. Nutritional and Physiological Significance. Chapman Hall, London, pp $152-163$

17. Uauy RD, Birch DG, Birch EE, Tyson JE, Hoffman DR 1990 Effect of dietary omega-3 fatty acids on retinal function of very-low-birth-weight neonates. Pediatr Res 28:485-492 
18. Carlson SE, Cooke RJ, Werkman SH, Tolley EA 1992 First year growth of preterm infants fed standard compared to marine oil n-3 supplemented formula. Lipids 27:901-907

19. Carlson SE, Werkman SH, Peeples JM, Cooke RJ, Tolley EA 1993 Arachidonic acid status correlates with first year growth in preterm infants. Proc Natl Acad Sci U S A 90:1073-1077

20. Usher RH, McLean F 1969 Intrauterine growth of live-born Caucasian infants at sea level: standard obtained from measurements in seven dimensions of infants born between 25 and 44 weeks of gestation. J Pediatr 74:901-910

21. Dubowitz LMS, Dubowitz V 1977 Clinical assessment of gestational age in newborns infants. J Pediatr 77:1-19
22. ESPGAN 1987 Nutrition and feeding of preterm infants. Acta Paediatr Scand Suppl 336:1-14

23. Koletzko B, Thiel I, Abiodun PO 1992 The fatty acid composition of human milk in Europe and Africa. J Pediatr 120:S62-S70

24. Putet G, Rigo J, Salle BL, Senterre J 1987 Supplementation of pooled human milk with casein hydrolysate: energy and nitrogen balance and weight gain composition in very low birth weight infants. Pediatr Res 21:458-461

25. Brossard N, Croset M, Pachiaudi C, Riou JP, Tayot JL, Lagarde M 1996 Retroconversion and metabolism of (13C) 22:6n-3 in humans and rats after intake of a single dose of (13C)22:6n-3-triacylglycerols. Am J Clin Nutr 64:577-587 